\title{
CONTEXT: THE STRATEGIC MANAGEMENT ROSETTA STONE
}

\author{
RV Weeks, University of Pretoria, South Africa
}

Purpose: The purpose of this paper is to analyse context as a means for interpreting and making sense of evolving strategic management theory and practice.

Problem investigated: Traditional strategic management theory based on rational deductive methodologies assumes contextual predictability, yet contemporary conditions tend to contradict this assumption. In response, alternative theories and practices for dealing with complex contexts have emerged (Brews \& Purohit, 2006; Grant, 2003; Kurt \& Snowden, 2003 and Stacey, 1995).

Methodology: A literature study was undertaken to determine the nature of emergent strategic management theory and practice, in response to contextual complexity and how it differs from traditional practice (Mintzberg, 1994 and Weeks \& Lessing, 1993).

Findings: An important conclusion drawn from the study is that context acts as a determinant for making sense of the evolution of strategic management theory and practice. While traditional strategic management practice still assumes relevance in contexts of linear causality, it breaks down in complex contexts. Emergent strategic management theory, based on complex adaptive systems, is increasingly assuming relevance. Notably, many institutions are still attempting to make use of scenario planning in an attempt to deal with contextual complexity, a practice not supported by leading researchers (Stacey, 1995 and Kurt \& Snowden, 2003).

Value of the research: The insights gained from the study assume relevance, in view of the contextual complexity confronting modern-day institutions. The findings suggest that emergent strategy based on complex adaptive system theory needs to be considered as a means for dealing with increasing environmental turbulence.

Conclusion: It is concluded that context serves as the Rosetta stone for making sense of strategic management theory and practice. In view of the research findings, as reflected in the literature, it would seem that the use of complex adaptive systems theory is gaining in relevance, as a means for dealing with complex contexts. Also important is the finding that traditional and emergent practices can in effect coexist, depending on context.

Key words and phrases: Complex adaptive systems; contextual complexity; complexity theory; strategic management; emergent strategy; scenarios; complicated and complex systems; globalisation; innovation.

\section{INTRODUCTION}

"A century that began with horses as the primary mode of transport culminated with astronauts in space stations, a race to unravel the great puzzle of the human genome, and calculating machines so powerful that they best people at intellectual challenges long thought to be the domain of human reasoning ... we must define $21^{\text {st }}$ century innovation as beginning at the intersection of innovation and insight: we innovate when a new thought, technology, business model or service actually changes society."

IBM Global Innovation Outlook, 2004

The introductory quotation attests to the dramatic nature of change that has engulfed mankind, dramatic changes that have left their footprints through time but that are of little value in revealing where we will be in the future. In 1994, South Africa gave birth to a new democratic dispensation, an event that subsequently has given rise to a context that, in many respects, is fundamentally different from the sociopolitical and economic dispensation that existed prior thereto. The various interactions and negotiations that took place and lead to the eventual new dispensation were complex in nature and the final outcome was certainly difficult to predict. In an attempt to make sense of the possibilities that existed, Sunter 
$(1987: 41,106)$ and his team developed what became known as the high and low road scenarios. At best, they constituted a description of possible future states that could emerge in a world of uncertainty.

South Africa, as it once again became integrated within the global economy free of sanctions, was subjected to a host of environmental forces that collectively have had a major impact in shaping the present-day business context confronting South African enterprises and it would have been difficult in 1994 to predict with any degree of certainty what the outcome would be. Asked to describe the events that have given rise to the present-day context, most South African executives and managers would be able to provide a large number of stories or narratives, each reflecting a specific aspect of the transformation that has taken place. These would, like a jigsaw puzzle, need to be placed together to provide a holistic perspective of how we arrived at the current reality confronting the business community. Retrospectively, this would be possible yet, in 1994, predicting the course of events and the future context that would emerge would certainly have been near impossible in view of the numerous interacting contextual determinant variables involved. This reality has very important implications when seen from a strategic management theory perspective. As noted by Davenport et al. (2006:25), "in the more turbulent world of the innovation economy, traditional approaches and structured processes to strategic management can no longer cope with the complexity ... requiring new solutions that involve fundamental transformation of strategic management thinking".

With the introduction as reference, in the subsequent section, the changing nature of strategic thinking is briefly elucidated in relation to context, thereby providing a preliminary insight into the influence of context on strategic management thinking. On the basis of this insight, in the ensuing section, three contextual ontologies of causality (complicated, complex \& chaos) are analysed with reference to corresponding strategic management epistemology, based on the assumption that context serves as the Rosetta Stone for interpreting strategy. Within this setting, contextual complexity is then analysed with reference to "strategy-as-emergent-process' and the implications for South African institutions.

\section{TRADITIONAL VERSUS EMERGENT STRATEGIC THINKING}

At the very core of traditional strategic management theory has been the need to attempt to predict the future so as to formulate and implement strategies that would optimally position the enterprise within its future environmental context (Devenport et al., 2006:68 and Weeks \& Lessing, 1993:22). In a world of relative stability where cause - effect relationships could be determined and trends extrapolated, possible future contextual conditions could be predicted with some degree of certainty. In such a context, traditional strategic management practice based on future predictions and scenarios made sense and various processes were developed by researchers to position the enterprise to take advantage of potential environmental opportunities and deal with contextual threats that may exist, while taking internal strengths and weaknesses into consideration. The SWOT (Strength, Weaknesses, Opportunities, and Threats) analysis, as it has become known, in fact formed a core component of many of the strategic management process variations that came into being at the time in question. A central tenet of traditional strategy formulation therefore relates to a need to gain an understanding of the future context within which the enterprise will function. As environmental instability increased and unanticipated events occurred that fundamentally changed the context in which institutions functioned, so researchers attempted to find new ways of dealing with contextual complexity and chaotic contextual situations.

Clearly, in analysing strategic management theory and practice, the context in which it originated is without doubt a crucial determinant. Context in effect serves as a Rosetta stone for interpreting and making sense of strategic management theory and practice as it evolved over the space of time. A significant component of strategic management literature has its origins in an industrial era of scientific management that has moved from relative environmental stability to one where change has become the norm rather than the exception to the rule. Traced over time, strategic management literature therefore in effect constitutes a history of the evolution of the concept from humble beginnings to become a fully fledged discipline and field of study. 
The proliferation of strategic management literature attests to the importance attributed thereto as a field of study. It in essence served to provide direction for the enterprise and gave meaning to its activities in terms of what executives hoped to achieve. Strategic management researchers and authors tend to reflect a specific aspect of the concept as it relates to the prevailing environmental context and the challenges confronting executives at the time in question. In the process, various schools of thought in relation to strategic management came into existence, each reflecting a specific aspect or perspective in relation thereto. So, for instance, the process of scenario development was researched as a means to explore possible alternative future contexts that may emerge. In the event of such a scenario materialising, executives having thought through the impact thereof on the enterprise would be well positioned to put in place appropriate well thought through strategies to effectively respond thereto.

Most traditional strategic management thinking is based on the concept of rationality and order, and the assumption that there is an underlying relationship between cause and effect that can be determined (Davenport et al., 2006:68). In a context where the future tends to be more blurred and consequently more difficult to predict, cause-effect relationships may not always be all that easy to determine. People may also not always be all that rational in the decisions that they make and executives and managers consequently needed to deal with far greater levels of uncertainty and ambiguity in formulating and implementing strategy within their corporations. The belief that unknown cause-effect relationships could be discovered by means of appropriate research serves as a distinctive characteristic of the manufacturing and industrial era. The development of traditional management science theory, in fact, is rooted in the belief that systems are ordered (Kurtz \& Snowden, 2003) and clearly this had a significant influence on strategic management theory and research.

To approach strategy formulation with mental models that evolved in a context of reasonable stability, when confronted with an emergent reality shaped by a complex interaction of a host of variables (the outcome of which is unpredictable to say the least), is without doubt a recipe for grappling for reality in a mess. Tom Peters (2003:27), however, encourages one to enjoy the mess and stretch beyond entrenched comfort zones to try something new and learn something valuable along the way. While not directly stated in so many words, clearly inferred is the need for a sense of strategic innovation in meeting the challenges of an emergent future.

In dealing with turbulent contexts, traditional strategic management theory (essentially constituting a rational, logical, deductive process) has been found to be less effective in practice and, increasingly, executives and managers experience difficulty in strategically positioning the enterprise. In certain instances, the continued relevance of strategic management has even been questioned. In this paper, the focus therefore is on contextual uncertainty and a possible strategic management response in dealing therewith. The convergence of complexity and strategic management theory is explored as one such response.

\section{CONTEXT: THE ROSETTA STONE FOR INTERPRETING STRATEGY}

Many South African executives would tend to describe present-day environmental conditions as being very turbulent and, in reality, this would largely be the case. Yet, there are also environmental conditions, in particular of a short term nature, which can be predicted and dealt with by means of traditional strategic management practices. The business environment, in fact, could be conceptualised as constituting an ecosystem composed of various interacting contextual determinants that collectively impact on business and government institutions. Some of the determinants in question could well be predictable while yet others would tend to defy any attempt to predict the outcome they will have in shaping the future context in which the institution will function. These determinants can coexist and it is this reality that makes strategic management an extremely interesting and difficult task.

It would appear that, in many a case, executives tend to use strategic management practices that were developed to deal with relatively stable environmental conditions to position an enterprise in what could best be described as a turbulent context. The result being that, after a short period of time, significantly changing environmental conditions necessitate a review of the institution's strategy and consequently few 
strategies are in fact implemented without being adapted along the way, a process often referred to as emergent strategy (Mintzberg, 1994:24).

Various researchers have come to question the use and relevance of traditional strategic management theory and its underpinning assumptions in dealing with contexts that have changed quite significantly. So, for instance, Davenport et al. (2006:6), in discussing the challenge to traditional concepts of strategy, cautions that "the turbulence and significant shift in the environment towards a knowledge-networked society ... and increasing evidence of company failures due to traditional business models and strategy approaches, imply that traditional ways of articulating strategy and practicing strategic management have to be seriously reconsidered'. Grant (2003:515), in a similar vein, concludes (from research studies undertaken) that strategic planning practices have undergone significant change over the last two decades in response to the challenges of turbulent and unpredictable environments. It is therefore suggested that context is the Rosetta stone for interpreting strategic process. While traditional strategic management theory still has relevance in ordered contexts where cause-effect relationships can be determined, alternative practices needed to be considered in dealing with complex and chaotic states.

Environmental turbulence conceptually is broad in nature and tends to embody the notion of both complex and chaotic contexts. A common characteristic of such turbulent environmental conditions is the fact that predicting the future, at best, constitutes crystal ball gazing and executives are not normally trained in the skills or art thereof. It is suggested that little purpose will be served in so doing and complexity theory is therefore proposed as an alternative consideration for dealing with turbulent contexts.

Cilliers (1998:3) draws an important distinction between complex and complicated systems. Complicated systems can in fact be broken down into their constituent components and analysed to gain an understanding of the system. A motor car or jet engine, while having a large number of components that collectively appear to be quite complex in nature, can in fact be taken apart and the individual components can be analysed in terms of their respective function. The parts can then be put together again and an understanding of how the components interact to propel an aircraft or car can be acquired. Such a system is essentially a complicated but not a complex system. Living systems tend to be complex in nature as one can hardly take them apart and put them together again to understand how they function. The difficulty that arises is that one cannot readily determine or observe the non-linear relationships that exist between the large numbers of components constituting a complex system. Snowden (2002) also draws a clear distinction between complicated and complex systems. According to Snowden (2002), in complicated systems cause and effect can be separated and, by understanding their linkages, we can control outcomes. In contrast, however, cause and effect cannot be separated in complex systems because they are intimately intertwined. In the case of complicated systems, one is therefore able to identify all the various components of the system and manage their interrelationships whereas, in complex systems, the outcomes are emergent in nature.

Traditional scientific management theory is based on the assumptions underpinning complicated systems and constitutes an important management paradigm of the manufacturing and industrial era. In this regard, typical cases in point are the concept of best practice, total quality management and business process re-engineering, to name but a few. It is therefore not surprising that traditional strategic management theory is also based on the assumption of complicated contexts, one where cause and effect relationships can be determined and analysed. As the relationship between cause and effect is linear in nature, trends can be extrapolated into future strategies.

Stacey (2003:19) conceptualises the scientific methodology in terms of the "individual scientist who objectively observes nature, formulates hypotheses about the laws governing it and then tests these laws against quantified data, so progressively moving towards a fuller and more accurate understanding of the laws. These laws were understood to take the form of universal, timeless, deterministic, linear 'if-then' causal links". The methodology described reflects much of our understanding of traditional strategic management where the accent is on rational deductive logic directed at gaining an understanding of the environmental context in which the enterprise functions and determining best practices in responding 
thereto. Within complex states, the cause-effect relationships are not deterministic and their outcomes are emergent in nature. One cannot therefore assume a best practice solution as each situation will tend to be unique in context and response (for instance the accent placed on innovation to gain a competitive advantage in a highly competitive global market place).

Having noted the difference that exists between complicated and complex systems, an additional distinction is introduced, namely that of chaos. As in the case of complex contexts, chaos states defy any form of prediction, as all connections have broken down and institutions are in a position of turbulence or eternal boiling (Snowden, 2002). In this regard, it is significant to note that Snowden (2002) warns against confusing complex with chaotic. "In a complex domain we manage to recognise, disrupt, reinforce and see the emergence of patterns; we allow the interaction of identities to create coherence and meaning. In a chaotic domain, no such patterns are possible unless we intervene to impose them; they will not emerge through the interaction of agents" (Snowden, 2002). Clearly, an important distinction between complex and chaos contexts is the fact that, in the former, patterns emerge from the interaction that takes place between the large numbers of components that constitute the system, while in the latter, no such patterns exist. Snowden (2002) concludes that, within chaos contexts, the decision model "is to act, quickly and decisively, to reduce the turbulence; and then to sense immediately the reaction to that intervention so that we can respond accordingly."

In discussing how complexity differs from chaos, Axelrod and Cohen (1999:xv) contend that chaos deals with situations such as turbulence that rapidly become highly disordered and unmanageable. In contrast, complex systems, composed of many interacting agents, may have a great deal of structure that may permit improvement by thoughtful intervention. Central to the concept of complexity, is the notion of the emergence of patterns that can be detected, but that cannot be predicted. Axelrod and Cohen (1999:4) refer to this in the sense of business strategy as including "patterns of response that pursue goals with little or no deliberation".

Grant (2003:491), in researching strategic planning in turbulent environments, contends that "increased volatility of the business environment makes systematic strategic planning more difficult" and "rapid changes require strategies that are flexible and creative". In describing the impact of environmental turbulence on strategy formulation, Grant (2003:493) refers to economic and market forecasts which he suggests provides the foundation for strategic planning and concludes that the "inability to predict demand, process, exchange rates and interest rates represent a fundamental change to companies' ability to plan". It would therefore appear that Grant identifies the unpredictability of the future context in which the organisation will function as a fundamental constraint in the formulation of strategy. Grant (2003:493-494) refers to scenario planning, strategic intent and the role of vision, strategic innovation and complexity and self-organisation, as possible attempts for reconciling systemic strategic planning with turbulent, unpredictable environments.

Features of strategic planning revealed, from the study undertaken by Grant (2003:515), suggest that "much of the debate between the 'strategy-as-rational-design' and 'strategy-as-emergent-process' schools has been based upon a misconception of how strategic planning works in the real world. The process of 'planned emergence' ... is consistent with management principles derived from complexity theory and observations of complex adaptive systems, and offers insights into the design principles of the multidivisional firm". The inference drawn from Grant's study that complexity theory has relevance in researching strategy within turbulent environmental contexts is deemed to be of particular interest. Following in a similar trend, Brews and Purohit (2007:73) conclude that "the higher sensitivity of Transactive Planning to environmental instability when compared with Rational Planning indicates that an increase in emergent over deliberate strategy is more likely in unstable environments".

From the preceding brief discussion, three contexts for interpreting strategic management in terms of process and content are identified, namely: complicated, complex and chaotic. Snowden (2002), however, divides the complicated context into two domains, that of known and knowable. In the former, "cause and effect relationships are generally linear, empirical in nature and not open to dispute" Snowden (2002) and therefore predictable, while in the later, cause and effect may not be fully known, but may be 
able to be discovered by means of appropriate fact-finding or research. The resultant four domains constitute core contexts of the Cynefin framework, which Kurtz and Snowden (2003) term to be "a sense making model designed to allow boundaries to emerge through the multiple discourses of the decision making group". With the preceding discussion serving as reference, contextual complexity is analysed in the next section

\section{CONTEXTUAL COMPLEXITY}

A central tenet of complexity is the notion of a large number of agents or elements interacting dynamically on a non-linear basis with positive and negative feedback loops giving rise to emergent contextual conditions. It is a description that seems to embody many of the characteristics of globalisation. Information and Communication Technology (ICT) has played a significant role in shaping the emergent global business environment which has moved from an industrial to an increasingly service orientated environment. Thomas Friedman in researching the globalised world of the twenty-first centaury, proclaims that the "World is Flat" (Friedman, 2006:5), the underpinning rationale being the convergence of technologies that enables world wide collaboration in providing services on an innovative basis. Service systems, according to Maglio et al. (2006:81), are value-creation networks composed of people, technology and organisations. The researchers contend that formal representation and modelling of service systems is complex in that a host of interacting elements are inherent to the system (Maglio et al., 2006:81). It could therefore be argued that services tend to be a function of interacting human attributes and variables that are brought together in the use of technology in service provision and it is this reality that adds to the complexity and consequential turbulence of the global marketplace.

Global markets are no longer the playing fields of only large multinationals, but the extensive networks of fibre optic cables that span the globe has enabled large numbers of small to medium enterprises to enter what has become a highly competitive marketplace. Electronic network technologies have in effect removed many of the geographical and institutional boundaries that restricted access to and interaction within global contexts. Consequently, the numerous human interactions that take place within global markets introduce a host of cultural and behavioural determinants that have an impact on shaping the business context. Add to the picture socio-political, ecological and economic elements that are also all interacting to shape the global context, and the complex nature of the context will become far clearer. Without doubt, collectively, the interacting elements and their impact in shaping what at best can be described as a continuously emergent marketplace would tend to be very difficult to predict with any degree of certainty. There are, however, definite patterns that would seem to be emerging from this global context that need to be taken into consideration from a strategic management perspective. Global warming and epidemics would seem to be typical such patterns that are increasing in relevance. The shift from an industrial to a services economy is another pattern that would seem to be emerging. The detail embedded within these patterns, however, is fuzzy and small interventions by governments, business institutions and communities could give rise to unexpected and unintended outcomes.

The volatility of the global energy marketplace and the impact thereof on most business institutions are of strategic consideration. Events in Nigeria, Iran, Iraq and the Soviet Union are of escalating global concern and contextual volatility in terms of the supply of oil and gas are scenarios that many an enterprise is taking into consideration. There are spin-offs in terms of electricity generation and research into alternative sources of energy is increasingly gaining ground. Nuclear energy, in particular, is increasingly a contender that will have an impact on the energy market. The nervousness, uncertainty and tension that exists in global energy and consequently economic markets translates into a situation were relatively small events can give rise to contextual situations that will have major outcomes in terms of the business operations of an enterprise. Traditionally, economic and market forecasts formed important determinants in the formulation of business strategies, yet the inability to predict the supply and demand, as well as the costs associated with energy that forms the life blood of so many institutions, constitutes a significant challenge to executives attempting to position their enterprises in the global marketplace. It is challenges such as this that Grant (2003:493) contends reinforce the case against formal strategic planning. 
The strategic planning cycles of the seven oil majors, as depicted in the research undertaken by Grant (2003:498), reveals that four make use of scenarios as alternative views of possible developments in the energy sector of the global economy. The accent, according to Grant (2004:493), of multiple scenario planning is "not to predict the future but to envisage alternative views of the future in the form of distinct configurations of key environmental variables". In a similar sense, the World Economic Forum (2007) views scenarios as stories about the future and good scenarios are deemed to be plausible, challenging and rigorously constructed to address the most critical questions that decision-makers face. This is in line with Schwartz's (1991:4) definition of scenarios as a tool for ordering one's perception about alternative future environments in which one's decisions might be played out. Implied is that they assist executives in being able to rapidly respond in the event of one of the envisaged scenarios materialising in practice. In this regard, they could serve as a means to assist in the development of contingency strategies. Many an enterprise, particularly when it comes to ICT, put in place a strategy to deal with events that could have a significant impact on it's business operations. With the importance of computer infrastructures and the associated databases to the operations of the modern-day enterprise, most intuitions have some sort of disaster recovery strategy in place. They are devised to bring order and recover from chaotic states that may arise from a fire or a similar catastrophe, resulting in a consequential loss of the institution's computer infrastructure that is deemed to be business critical.

It is interesting to note that Kurtz and Snowden (2003) consign scenario planning to the knowable domain and therefore within an ordered environmental context where cause-effect relationships can be determined and not within either complex or chaos domains, where such relationships at best can be retrospectively determined in complex contexts. This tends to stand in contradiction to practice, as previously noted, within the oil sector (Grant, 2003:493). As far as chaotic contexts are concerned, Stacey (1992:66) argues that "it is completely impossible, even in principal, to predict specific outcomes" and "the only scenario of any use is the one which will emerge in real time and to identify it you will have to wait and see what happens". In this sense, Stacey and Snowden therefore appear to be in agreement as to the affectivity of scenarios in developing strategy within complex and chaotic states. Stacey (1992:66), however, acknowledges that it may be useful to use scenarios to learn in advance how to deal with general kinds of situations that might arise, but warns that such an exercise is hypothetical and the real situation will be different. This, it would seem, would apply to contingency strategies for dealing with potential computer infrastructure failure, with the realisation that the actual situation could differ in many respects.

With the large number of participants actively engaged in global markets, it is only to be expected that a highly competitive context would emerge. Within such a context, a strategic objective would be to gain some sort of competitive advantage over competitors. The World Economic Forum Global Competitive Index $(\mathrm{GCl})$ provides an overview of factors that are critical from a national productivity and competitive perspective. The factors concerned are: health and primary education; macroeconomics; institutions; higher education and training; infrastructure; market efficiency; technological readiness; business sophistication; and innovation. Collectively, these factors provide a picture as to various countries' competitive profile, yet in a dynamic context any ranking can at best provide a snapshot, in time, of the existing situation. Of particular pertinence in analysing the factors is the interrelationship that exists between these factors, including their relevant components and in reality it would tend to suggest a complex context that, in terms of future rankings, would be very difficult to predict. Business institutions therefore are in fact subjected to a host of interacting contextual variables at a national and global level that would make scenario development extremely difficult, as changes in any single determinant can have major implications in terms of other determinants and consequently of the actual scenario that emerges at any point in time.

With the above in mind, it is interesting to take note of the use still being made of scenarios in strategy formulation. So for instance the "India and the World: Scenarios to 2025" project explores three potential directions that may emerge, namely the Bolly World, Atakta Bharat and Pahale India scenarios (World Economic Forum, 2005). In this regard, they serve a similar purpose to the South African "high and low road" scenarios (Sunter, 1987:41,106) previously alluded to, where there is a clear desired future that it is hoped all institutions would be working towards. The scenarios tend to be broad in nature and not very 
detailed and are more in line with presenting a preferred future state, while the other more negative scenarios, presenting a contradictory less desired state serves as a motivator for directing activities towards the former. In the case of India, the "Pahale India" (India First) scenario describes the country as being unified with the people putting the needs of their communities and the country first, resulting in India emerging as a global economic leader. In contrast, the "Bolly World" scenario describes an India where initial economic success turns out to be unsustainable, with domestic and demographic pressures triggering an economic reversal. Clearly, this presents an image that people would hardly like to see materialise. Similarly, the "Atakta Bharat" scenario also paints a negative picture, one where India lacking unified action and effective leadership encounters continuous and cumulative difficulties. The desired state presented could serve as an attractor, but as previously suggested by Stacey (1992:66), the reality could be something quite different.

Traditional strategic management theory and practice embodies the use of vision, mission and value statements. It could be argued that vision statements are closely aligned with the concept of scenario development in contexts of uncertainty. The contention by Burt Nanus (1992:105) that: "with three or four scenarios of the future external environment of your organization, you are now in a position to draw tentative conclusions for your vision statement', attests to this. Implied is a notion of rational deductive reasoning in developing a mental model or construct of a desired future that acts as an attractor for all organisational activity in order to bring some sort of stability in a world of turbulence. In reflecting on the failure of vision statements, Nanus (1992:32-32) acknowledges that "sometimes they are overtaken by events and become obsolete before they can be realised". This would resonate with Stacey's (1992:66) concern that, all too often, reality is quite different from that initially expected. It is suggested that the actions taken in order to realise the vision created for an institution in fact constitutes interventions that, within a complex domain, could have unexpected consequences, as small changes in initial conditions could give rise to major contextual shifts, as a result of positive feedback mechanisms, in interacting with numerous other environmental determinants.

It is significant to note that the World Economic Forum (2007) views scenario thinking as providing "a tool to focus thoughts around the future, to recognize, understand and challenge the assumptions and uncertainties related to the context we operate in and its evolution". While noting that scenarios "are neither an end to themselves, neither absolute nor exhaustive answers to future uncertainties", the World Economic Forum (2007) goes on to suggest that they are "a powerful management tool to improve the quality of executive decision making". Based on this assumption relating to the use of scenarios, the World Economic Forum has assisted Russia and China to also develop a set of scenarios along the line of those, dealt with above, for India. Their thinking in this regard has clearly been influenced by the fact that there are large international corporations that still make use of scenario planning, this is clearly depicted by their following statement: "leading global companies often engage in constructing large-scale scenarios to help formulate their business and investment strategies" (World Economic Forum, 2007). As previously seen, the research findings of Grant (2003:498) also confirms that there are in fact still major oil corporations that adopt such an approach in dealing with contextual turbulence.

From the preceding discussion, it would seem that the use of assumptions on which scenarios are based as a means for dealing with turbulent contextual conditions, poses some very important fundamental questions that need to be taken into consideration. In particular, the contention that, within complex contexts, totally different and unexpected contextual conditions could emerge needs to be considered. It would, however, seem that the assumptions underpinning scenarios and the strategic practice associated therewith have become ingrained in management thinking and in certain instances practice as well. It is suggested by Houchin and MacLean (2005) that "the strategy field needs a new paradigm to break from the limitations of existing mindsets" and that "complexity theory may be the theory to do this, reconciling the essential unpredictability of industries and organizations with the emergence of distinctive patterns".

The contextual complexity that confronts the management of both public and private sector institutions, in effect, stems from dynamic system interaction resulting in sudden and unexpected changes that more often than not were hardly expected. It is, for instance, doubtful if any of the institutions that had offices or facilities within the Twin Towers buildings in New York would have considered scenarios even vaguely 
representing the reality that occurred on 11 September 2001. The chaos that subsequently materialised and the sequence of events that followed, gave rise to contextual conditions that have had a very significant impact on many institutions. The current situation that exists in Iraq and the business institutions operating there is another case in point. If one considers the sequence of events that have given rise to the volatility that currently exists within global oil markets and that have sent the price of oil souring, one can only speculate at how many institutions had taken any of these events into consideration in formulating their strategies. The emergent pattern of global warming and the sequence of contextual conditions that will in future stem there from can at best constitute an educated guess. There are warnings as to what could happen if the bird flu virus were to mutate and cross over to humans and just how many institutions have given thought to such an occurrence and the impact thereof on their operations is also open to conjecture. It would therefore seem that patterns are constantly emerging within the economic, political, ecological and social environment that are giving rise to contextual conditions that will have varying degrees of impact on institutions, are difficult to predict the outcome of, and that at best can be described as being complex in nature.

As noted in the introduction, an assumption underpinning traditional strategic management practice is one of optimally positioning the institution within its external environmental context so as to gain a competitive advantage taking internal strengths and weaknesses into consideration. An internal and external contextual assessment therefore informed the strategic decision making process, taking the mission, vision and values of the institution concerned into consideration. A key tenet in formulating strategy being the need for some form of stability and a sense of direction in terms of what the institution hoped to achieve within a specified time frame. The volatility of a complex environmental context brings into question the practical limitations of predictability associated with such a process. The importance of information as a critical resource in strategic decision making has gained in pertinence as a direct consequence of constant contextual changes that materialise and an accent has been placed on ICT and electronic information systems in view of the information overload that has ensued. Business and competitive intelligence has in this sense assumed a fundamental role in most modern-day business, industry and public sector institution's decision making processes, as a result of the contextual complexity these institutions need to deal with. According to Keyes (2006:159), business intelligence serves as the radar used by institutions for scanning the environment, so as to avoid dangerous situations that may be emerging and for seizing opportunities that may be presented. Meyer (in Keyes, 2005:159) describes it as "the other half of strategic planning" in that it monitors strategy implementation and assists in making strategic course corrections along the way. Inferred therefore is the use of business intelligence as a means of making an emergent strategy implementation process possible. A key issue in this regard will be just how effective business intelligence systems are, in practice, in detecting emergent patterns within complex contexts and in assisting executives in the interpretation thereof.

Seen within the context of a highly competitive global market place, there appears to be an accent placed on the need for innovation for strategically dealing with the complex nature thereof. In this sense, innovation could not only act as a means for providing an institution with a competitive advantage, but in addition act as a catalyst for contextual turbulence. This is particularly relevant within a context of cutting edge technology where the innovative use thereof, against a background of an increasingly complex global economy, is able to provide even small to medium business institutions with opportunities. The innovative use of electronic network technologies in outsourcing services to low cost service providers, such as in Bangalore, Singapore, South Africa and China, has for instance provided companies, like IBM and others, with a cost advantage in packaging business solutions for clients. In the process, the services industry has experienced an emergent pattern in relation to service rendering, in that scarce ICT skills have now emerged as becoming a critical issue. This example serves to demonstrate the complex nature of the prevailing business environment, where small changes in one system hold the potential to engender larger unexpected outcomes in another by means of positive feedback loops.

From the discussion, it may be concluded that contextual complexity has become a reality that institutions need to live with. It, however, does not imply that more stable ordered contexts cannot coexist with complex contexts at any point in time. From a strategic management process perspective, a differentiation needs to be made in order to apply the correct methodologies and interventions applicable 
to the context concerned. As the literature in relation to traditional strategic management processes used within ordered contexts is very extensive, this will not be addressed in the following discussion, the accent will rather be on dealing with complex and chaos contexts from a strategic management perspective. The problem of turbulent contexts is hardly a new phenomenon and researchers have viewed the problem from both a pro- and re-active perspective, the former would of necessity entail some form of future assessment and thus the notion of the use of scenarios that provide some form of future projection that may be used for planning. As noted from the preceding discussion, the actual context that could emerge could be quite different from that envisioned and this would imply that the strategy developed would need to be revisited on a continuous basis, thus the consideration given to emergent strategy, which forms the central precept of the subsequent discussion.

\section{STRATEGY: AN EMERGENCE PERSPECTIVE}

The evolution of strategic management process considerations has largely been driven by the practical realities associated with managing an enterprise within a specific context. As the context became more difficult to predict, so new methods were developed in response to the changing contexts encountered in practice. Important characteristics of the modern-day context in which institutions function relates to complex contexts that are highly competitive and consequently a lot of effort is placed on strategy for gaining a unique competitive advantage within dynamic competitive contexts. Emergent strategy can be seen as constitution small incremental adaptive thrusts that are constantly reviewed in the light of changing contextual conditions. In a sense, this constitutes a reactive approach and, as noted by Davenport et al. (2006:72), "emergent strategies are the result of a learning approach" which "changes the character of the concepts and techniques commonly utilised in the prediction approach". It is suggested by Davenport et al. (2006:72) that, within a highly competitive context, the task of strategic management is one of managing adaptation and the only competitive advantage would be the ability of the institution to learn faster than the competition. It is also argued that innovation could play a major role in this regard.

Mintzberg (1994:24-25) draws a distinction between deliberate, intended and emergent strategies. Emergent strategy is seen as a sequence of actions which converge into some sort of a pattern over a period of time without deliberate intention (Mintzberg, 1994:24-25). This would seem to suggest retrospective coherence where, once a pattern has stabilised, its path appears logical, but it is only one of many that could have stabilised, each of which would have also appeared logical in retrospect (Kurtz \& Snowden, 2003). An important element of such a strategy is both a need for innovation, flexibility and extensive participation, as no individual executive or manager could deal with the all numerous strategic challenges that confront the institution as they evolve. Because the challenges confronting executives and managers are more complex, strategic innovation requires a diverse mix of talent, insights, knowledge and expertise, which suggests mutual causality.

Emergent strategy, in a sense, entails a dimension of creativity and innovation in responding to patterns that emerge within a complex business context, in this sense it could well be described as constituting just in time strategic management. The strategy emerges from a continuous dialog and interaction of an institution's key decision makers with clients, staff, suppliers, politicians, and various diverse communities. It entails managing from the front line. Maurice Lévy (2007:56), group CEO and Chairman of Publicis (one of the world's largest advertising groups) states that "creative business like ours has a natural tendency to latch onto new ideas, and moving forward prematurely is an ever present danger." Lévy (2007:56) suggests that the executive committee is not always the best place to "smell the future". Their job, he claims, is to "listen and to interpret what we hear from people working and talking in the field ... as this work percolates we can start to pick out broader, global patterns, keeping ourselves ahead of the curve, but not too far ahead" (Lévy, 2007:56). This description of emergent strategy in practice brings together some of the key contemporary threads with an accent on innovation, extensive consultation with diverse communities, contextual emergent pattern identification and managing from the front lines.

Grant (2003:491) confirms that investigations of strategic decision making points to strategies emerging from the weakly coordinated decisions of multiple organisational members. As previously noted, the IBM 
Corporation in compiling its annual Global Innovation Outlook, has adopted what it terms to be a series of open, candid and freewheeling conversations about important issues of the day in order to tap into a broad ecosystem of contributors (IBM, 2006:48). This, in effect, constitutes a process of identifying emergent patterns within a complex environment by means of narrative techniques. The need for extensive and wide spread consultation is clearly deemed important in identifying the patterns concerned and, in the process, IBM executives and managers are brought into the front lines in interaction with participants and staff members from across the world in discussion forums. The accent placed on innovation by Sam Palmisano, Chairman and CEO of IBM, is also to be seen from his statement that "Innovation has been central to our company ... it's the primary reason our clients do business with us, and the simplest and truest statement of IBM's purpose" (IBM, 2006). It is therefore not surprising to find that Innovation forms an important component of the corporation's shared values.

\section{CONCLUSION}

A number of important conclusions may be derived from the above discussion. These are summarised as follows:

- $\quad$ Both traditional and more contemporary strategy based on complexity theory can coexist, with context serving as the Rosetta stone for determining the appropriate approach to be used.

- Within present-day contexts, environmental turbulence and unpredictability have become far more prevalent and the use of complexity theory and the associated emergent strategic approach serve as a means for dealing therewith.

- A review of contemporary literature seems to suggest that scenario management is still quite extensively used in practice by institutions in dealing with the challenges presented by contextual turbulence, yet a significant number of researchers have concluded from their research findings that such an approach is not effective.

- $\quad$ The need for widespread conversation forums with diverse communities and managing from the front lines is gaining ground in practice and innovation plays a key role in this regard.

With these conclusions serving as a frame of reference, it is suggested that complex adaptive strategy needs to be considered as a response for dealing with increasingly turbulent environments. Grant (2003:513), in a similar sense, captures the essence of contemporary practice, in stating that:

"The features of strategic planning revealed by the study suggests that much of the debate between the 'strategy-as-rational- design' and 'strategy-as-emergent-process' schools has been based upon a misconception of how strategic planning works in the real world. The process of 'planned emergence' evident in the companies' strategic planning systems is consistent with management principles derived from complexity theory and observations of complex adaptive systems."

The following possible implications for South African business institutions stem from the above conclusions:

- Traditional strategic and management practice are still relevant within complicated contexts, particularly of short term duration. The use of scenarios, as currently still used by some institutions, may well serve a purpose within such a context, but if contexts become complex in nature, the envisaged scenarios may not materialise, implying a need for emergent strategic management practice based on complex adaptive systems theory.

- National markets are generally far too small to constitute a solid basis for sustainable business growth and South African institutions need to take their place in a highly competitive global services economy, that in effect is extremely complex and turbulent in nature. In order to gain a 
competitive advantage within the global marketplace, innovation assumes significant strategic importance. This implies a need for widespread conversation forums with an open agenda and a propensity to learn, which has significant institutional culture implications for strategy.

- The need for aligning strategic management practice with context implies a shift in traditional strategic management thinking, one that embraces a 'strategy-as-emergent-process' for dealing with complex and turbulent contexts. For many institutions, this may entail a need for short courses for executives and managers, who have not been exposed to the narrative-based methodologies involved, as well as the strategic sense-making ontology framework.

\section{REFERENCES:}

Axelrod R \& Chohen MD. 1999. Harnessing complexity: Organizational implications of a scientific frontier. New York: Free Press

Brews P \& Purohit D. 2007. Strategic planning in unstable environments. Long Range Planning, 40:6483.

Davenport TH, Leibold M \& Voelpel S. 2006. Strategic management in the innovation economy. Germany: Wiley.

Friedman TL. 2006. The world is flat: The globalized world in the twenty-first century. London: Penguin.

Grant RM. 2003. Strategic planning in a turbulent environment: Evidence from the oil majors. Strategic Management Journal, 24(6):491-517.

Houchin K \& MacLean D. 2005. Complexity theory and strategic change: An empirically informed critique. British Journal of Management, 16:149-166.

IBM. 2004. Global Innovation Outlook 2004. Armonk, New York: IBM Corporation.

IBM. 2006. Global innovation outlook 2.0. Armonk, New York: IBM Corporation

Keyes J. 2006. Knowledge management, business intelligence, and content management: the IT practitioner's guide. New York: Auerbach.

Kurtz CF \& Snowden DJ. 2003. The new dynamics of strategy: Sense-making in a complex and complicated world. IBM Systems Journal, 42(3):462-483.

Lévy M. 2007. Look to your front line for the future. Harvard Business Review, 85(7):55-57,July-August.

Maglio PP, Srinivasan S, Kreulen JT \& Spohrer J. 2006. Service Systems, Service Scientists, SSME and Innovation. Communications of ACM, 49(7):81-85, July.

Mintzberg H. 1994. The rise and fall of strategic planning: Reconceiving roles for planning, plans, planners. New York: Free Press.

Nanus B. 1992. Visionary leadership. San Francisco: Jossey-Bass.

Peters T. 2003. Re-imagine! London: Dorling Kindersley.

Snowden D. 2002. Complex Acts of Knowing: Paradox and Descriptive Self-awareness. Journal of Knowledge Management, 6(2):May (special edition). 
Stacey RD. 1992. Managing the unknowable: strategic boundaries between order and chaos in organizations. San Francisco: Jossey-Bass.

Stacey RD. 1995. The science of complexity: an alternative perspective for strategic change processes. Strategic Management Journal, 16:477-495.

Stacey RD. 2003. Strategic Management and organisational dynamics. Harlow: Pearson.

Sunter C. 1987. The world and South Africa in the 1990's. Cape Town: Human.

Swartz P. 1991. The art of the long view. London: Doubleday.

Weeks RV \& Lessing N. 1993. Strategic Management: A turbulent environmental Perspective. Johannesburg: NZK.

World Economic Forum. 2005. India and the world: scenarios to 2025. WEF [Online] Available from: http://www.weforum.org/pdf/India/Scenarios_Executive_Summary.pdf.

World Economic Forum. 2007. Scenario planning. WEF [Online] Available from: http://www.weforum.org/en/initiatives/Scenarios/index.htm. 